\title{
The Geoscience Laser Altimeter System
}

\section{Laser Transmitter}

\author{
R. S. Afzal, J. L. Dallas", A. W. Yu* , W. A. Mamakos ${ }^{*}$, A. Lukemire ${ }^{\dagger}$, \\ B. Schröder", A. Melak** \\ NASA-GSFC Code 924.1 \\ Space Lidar Technology Center \\ 5004 College Ave \\ College Park. MD 2077 I \\ Rohert.teatiugsfonasagon
}

\begin{abstract}
The Geoscience Laser Altimeter System (GLAS), scheduled to launch in 2001, is a laser altimeter and lidar for the Earth Observing System's (EOS) ICESat mission. The laser transmitter requirements, design and qualification test results for this spacebased remote sensing instrument are presented.

(C)1999 Optical Society of America

OCIS Codes: (140.3580) Solid State Lasers, (140.3480) Diode Pumped Lasers, (280.3640) Lidar and (350.6040) Space Optics.
\end{abstract}

The Geoscience Laser Altimeter System (GLAS) ${ }^{1}$ scheduled to launch in 2001, is the sole instrument for the ICESat (Ice, Cloud and Land Elevation Satellite) mission. GLAS will be a satellite laser altimeter and atmospheric lidar whose primary mission is the global monitoring of the Earth's ice sheet mass balance. GLAS will also provide high precision land topography and global monitoring of aerosols and cirrus cloud heights. The current state-of-the-art in space based solid-state lasers is the Mars Orbiting Laser Altimeter (MOLA) $)^{2,3}$, on the Mars Global Surveyor spacecraft collecting topography data of Mars ${ }^{4}$. The GLAS laser will generally have an order of magnitude higher performance than MOLA in power, beam quality etc., and represents the next generation of space-based remote sensing laser transmitters. The laser transmitter will have the following performance characteristics: pulse energy-75 mJ@1 $\mu \mathrm{m}, 35 \mathrm{~mJ} @ 0.5 \mu \mathrm{m}$, repetition rate $-40 \mathrm{~Hz}$, pulse-width $<6 \mathrm{~ns}$, beam divergence $-110 \mu \mathrm{rad}$, beam profile - nominally Gaussian, $>4 \%$ electrical efficiency, with a 3 year ( 5 year goal) lifetime ( $>3$ billion shot lifetime/laser). In addition, the laser must be rugged, reliable and capable of long term operation in the space environment over temperature ranges expected by the instrument.

A master-oscillator, power-amplifier (MOPA) design is the most promising architecture for meeting the transmitter performance objectives ${ }^{5}$. A schematic of the optical layout within the laser housing is shown in Figure 1. The oscillator, pumped by two $100 \mathrm{~W}$ Q-cw diode-bars, is passively Q-switched, and generates 2 $\mathrm{mJ}, 5 \mathrm{~ns}$ near diffraction limited $\left(\mathrm{M}^{2}<1.1\right)$ pulses at $40 \mathrm{~Hz}$. The output pulses are expanded by a $2 \mathrm{x}$ telescope, and amplified by a double-pass preamplifier stage pumped by $8,100 \mathrm{~W}$ bars resulting in $15 \mathrm{~mJ}$ pulses with an $\mathrm{M}^{2} \approx 1.4$. This stage utilizes a polarization coupled double pass zig-zag slab with a porro prism for beam symmetrization. After another $2 x$ expansion, the beam enters a power amplifier pumped by $44,100 \mathrm{~W}$ bars. The pulses are amplified to $110 \mathrm{~mJ}$ after a double pass with an $\mathrm{M}^{2} \approx 1.8$. The peak laser fluence in the final amplifier is $4 \mathrm{~J} / \mathrm{cm}^{2}$. The full power beam is then directed to a Lithium Triborate doubler designed to convert $30 \%$ of the power into the green, followed by an achromatic, $6 \mathrm{x}$ final beam expander. Figure 2 shows the output energy and prime power draw by the diode power supply as a function of diode drive current. To improve laser lifetime ${ }^{6}$ oscillator diodes are derated to $65 \mathrm{~W} / \mathrm{bar}(85 \mathrm{~A})$ and the amplifier diodes are derated to $85 \mathrm{~W}$ ibar $(100 \mathrm{~A})^{7}$. The laser is all conductively cooled with the thermal interface to the spacecraft being a heat pipe mounted to a side-wall of the laser housing. Thermal 
control of the oscillator diodes and the doubling crystal must be accommodated and accounted for internally to the laser leading to a final prime power draw of $110 \mathrm{~W} @ 30 \mathrm{~V}$ input.

All materials and construction techniques have been carefully considered to ensure radiation tolerance, vacuum compatibility and opto-mechanical stability. Our preflight, vacuum compatible, engineering test unit (ETU) weighing $14.7 \mathrm{~kg}$, has undergone thermal-vacuum (TVAC) tests over multiple survival and operational cycles from 0 to $40^{\circ} \mathrm{C}$ and 10 to $30^{\circ} \mathrm{C}$ respectively, with no change in the laser performance after testing. The ETU has also passed vibration testing at 10.6 grms simulating launch conditions, demonstrating the design is ready for flight fabrication.

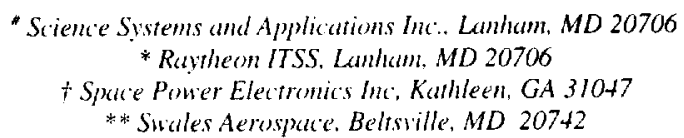

Reference:

1 Abshire, J.B. X. Sun. E. A. Ketchum. R. S. Afzal. P. S. Millar. "The Geoscience Laser Altimeter System (GLAS) for the ICESat Mission", OS.t Conference on Lasers and Electro-Oprics, San Fransisco, CA, May 2000.

2 Afzal. R. S. "Mars Observer Laser Altimeter: Laser Transmitter." Applied Optics. (33), 15. 20 May, 1994, p. 3184

3 Aizal, R. S.. "Space Operation of the MOLA Laser", OSA Advanced Solid State Laser Topical Meeting. Davos, CH, 2000

4 Smith. D.E. M.T Zuber. H.V. Frev, J.B. Garvin. J.W. Head. D.O. Muhleman, G. H. Pettengill, R. J. Phillips. S.C. Solomon, H.J. Zwally. W.B. Banerdt. T.C. Duxbury. Topography of the northern hemisphere of Mars from the Mars Orbiter Laser Altimeter. Science, Vol. 279, pp. 1686-1692, 1998.

5 Afzal, R. S., A. W. Yu. W. A. Mamakos, "The GLAS Laser Transmitter Breadboard", OSA TOPS Vol. 10. Advanced Solid State Lasers. p. 102 Orlando. FL, Jan. 27 - Jan. 29. 1997

6 Stephen, M. A. J. L. Dallas and R. S. Afzal, "Multi-billion shot, High-Fluence Exposure of Cr4t:YAG Passive Q-switch," SPIE Proceedings from $29^{\text {yh }}$. Ammal Boulder Damage Symposium, Vol. 3244, Boulder, CO, p. 517. Oct. 6. 1997.

7 Stephen, M. A.. M. Krainak, and J. L. Dallas. "Quasi-CW Laser Diode Bar Life Tests," SPIE Proceedings from $29^{\text {th }}$ Annual Boulder Damage Simposinm. Vol. 3244. Boulder, CO, p. 598. Oct. 6, 1997.

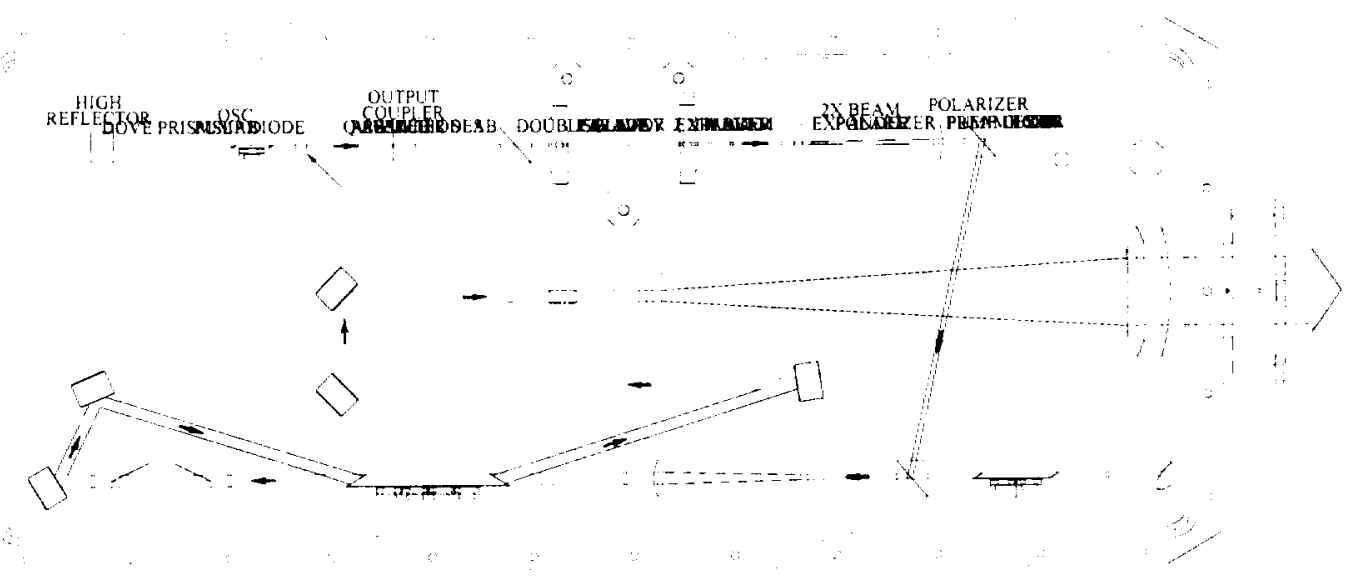

Figure 1 - Schematic of the optical layout in the GLAS laser housing. 


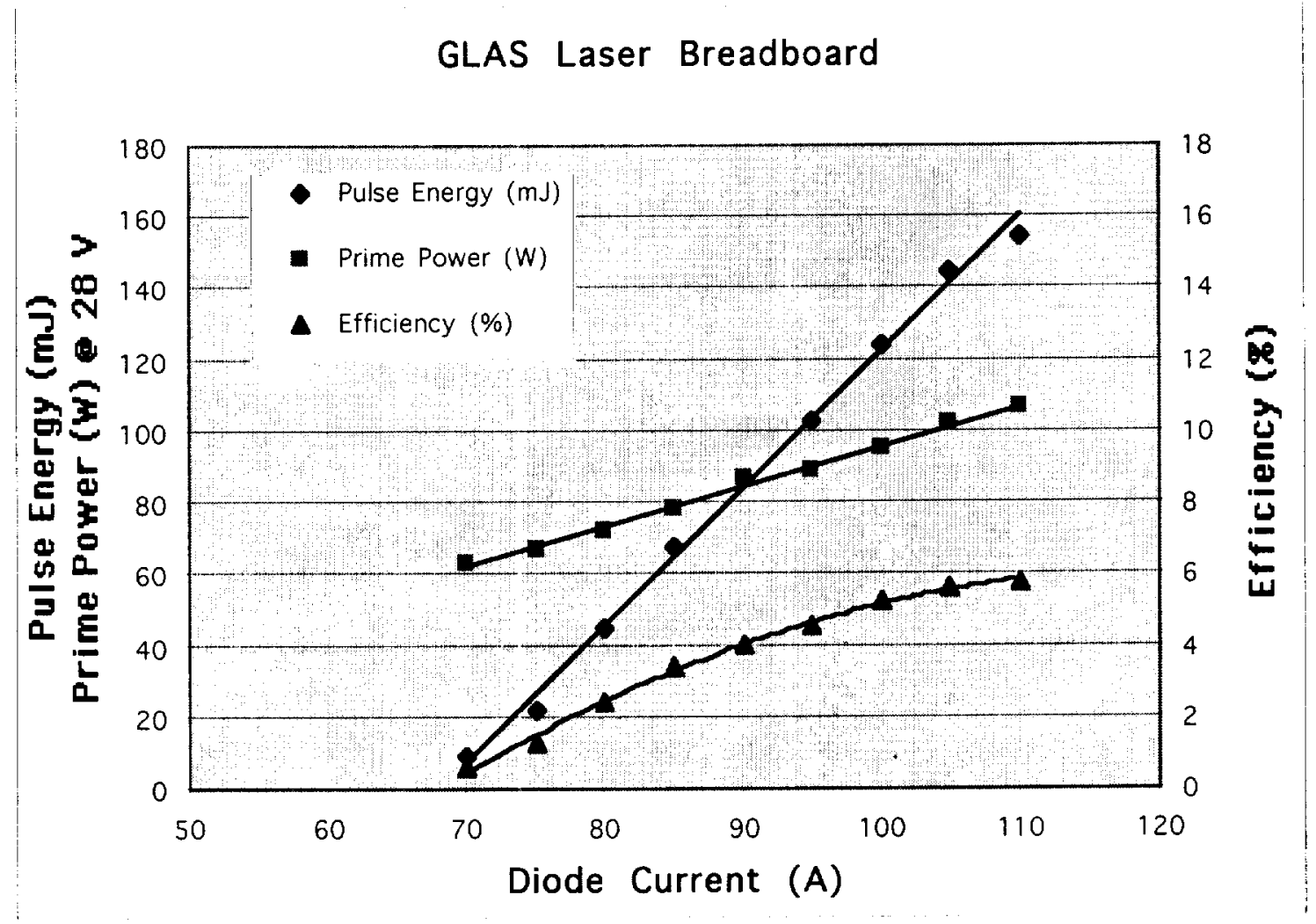

Figure 2 - Output pulse energy (at $40 \mathrm{~Hz}$ ) as a function of diode drive current. Also shown are the prime power usage from the diode power supply and the efficiency. This graph shows the laser architecture is capable of $160 \mathrm{~m} J$ pulse with the diodes operating at full power. The GLAS laser diodes are derated to $100 \mathrm{~A}$ during operation. 